\title{
Understanding and Predicting Behavioral Intent of Food Concessionaires on Solid Waste Management in a University Campus
}

\author{
Cecile V. Benitez ${ }^{1}$ \\ ${ }^{1}$ College of Hospitality and Tourism Management Bulacan State University, Malolos City, Bulacan, Philippines
}

\begin{abstract}
Background/Objectives: The Philippines' National Solid Waste Management reported that kitchen/food and other organic wastes comprises $50 \%$ of the total solid waste generated. This is the rationale that this study was undertaken to include the waste generators. Methods/Statistical analysis: The central question which the study sought to understand is whether attitude and knowledge relates to each other on the subject of solid waste. A descriptive and correlational design was adopted in the solid waste management survey for the food concessionaries of the university. The study involved all food concessionaries within the university compound. A questionnaire survey composed of four parts was used as instrument. Findings: The main result of the study found that the Attitude variable is positively correlated with Knowledge variable $(r=.418, p<.05)$ and it indicated that the relationship is significant. Perceptions on the 3Rs (reduce, reuse, and recycle) positively correlated with Attitude and all three factors are found to be significantly related with Attitude. Improvements/Applications: As to the mediating variables, i.e., Ease of Use, Usefulness, Volunteerism, and Facilitating Conditions, they were found to be explanatory with Knowledge rather than Attitude (particularly with Ease of Use and Volunteerism). Other mediating factors showed weak relationship with either Attitude or Knowledge. The food concessionaries were found to possess a positive attitude on the 3 Rs . With the assumption that the results of the study estimates that of the population, the research found a sound basis for predicting behavioral intent of the food concessionaires to practice solid waste management.
\end{abstract}

\section{Index Terms}

Food concessionaires, Knowledge and attitude, Behavioral intent, Ease of use, Usefulness, Volunteerism.

\footnotetext{
Corresponding author : Cecile V. Benitez

cecile.benitez@bulsu.edu.ph

- Manuscript received November 19, 2018.

- Revised December 6, 2018 ; Accepted December 14, 2018.

- Date of publication December 31, 2018.

(c) The Academic Society of Convergence Science Inc.

2546-1583 @ 2017 IJEMR. Personal use is permitted, but republication/redistribution requires IJEMR permission.
} 


\section{INTRODUCTION}

The annual growth rate of population in the Philippines ,from 2010 to 20015, is posted at 1.72 percent [1]. Philippine population stands at 100.98 million [1]. Studies show that population is known to influence the generation of solid waste depending on socio-economic and level of the region [2,3]. According to the World Bank [4], "the higher the income and urbanization the greater the amount of solid waste produced". Metro Manila generates about a quarter of the total solid waste generated in the entire country. The National Capital Region generates an estimated 0.71 kilogram per capita per day. The country's average solid waste ranges between 0.30 to 0.68 kilogram per capita per day. On a daily basis, the Philippines' total waste generated is estimated at 35 tons. [2]

Based on the study conducted on waste composition, the National Solid Waste Management reported that kitchen/food and other organic wastes comprises $50 \%$ of the total solid waste generated. Recyclables waste ranges between 42 to 49 percent. [2]

The National Solid Waste Management acknowledged the critical component of a successful waste avoidance is people's attitude [2]. Local studies conducted about attitude and/or knowledge and solid waste management suggest that attitude and knowledge ratings significantly explain the outcome for practice rating [5-7]. In a study conducted on food stall owners' and students' attitude and knowledge by $\mathrm{Camba}(2014)$, the results showed that high knowledge and positive attitude contributed to the observance to cleanliness and sanitation. Comparatively, food stall owners had shown to have high attitude and knowledge on school policies regarding solid waste management than students [6]. Similar study found out that waste generators have a more positive attitude than waste workers [7]. Students with higher level of knowledge were more likely to recycle and students' attitude towards reduction is secondary to recycling [8].Some study, however, belie the positive relationship of knowledge and attitude [9]

How knowledge and attitude affect behavioral intention and eventually into action or practice is found in Ajzen's [10] Theory of Planned Behavior. Ajzen theorized that an "individual behavior is driven by behavior intentions, where behavior intentions are a function of three determinants: an individual's attitude toward behavior, subjective norms, and perceived behavioral control." The theory posits that when there is a strong behavioral intention, the more likely the behavior will be performed. Attitude is the degree to which a person has towards the behavior [11]. Subjective norms is the perceived social pressure to perform the behavior
[10]. Perceived behavioral control is a belief about factors that make the behavior easy or difficult to perform.

\section{A. Purpose of Statement}

The main objective of the study is to understand whether attitude and knowledge of the food concessionaires are associated in terms of solid waste management practices. Specifically, the study seeks to answer the following questions:

1. What is demographic profiles of the subjects in terms of: Age, Gender, Job Position, Attendance to SWM seminars, number of years employed in the business, number of years in operations?

2. What is the attitude of the respondents in terms of Reuse, Recycle, and Reduce of solid waste management?

3. What is the relationship of Attitude with Knowledge?

4. How do the following mediating variables associate with Attitude and Knowledge : Ease of Use, Usefulness, Volunteerism and Facilitating Conditions.

\section{B. Conceptual Framework}

The framework of the study is divided into two main constructs namely: attitude and knowledge. Attitude is a function of beliefs or perceptions underlying solid waste management which are based on 3Rs of waste management such as reduce, reuse and recycle. The knowledge constructs are data or information related to waste management which the individual is aware of. Fig. 1 illustrate the relationship of the different constructs.

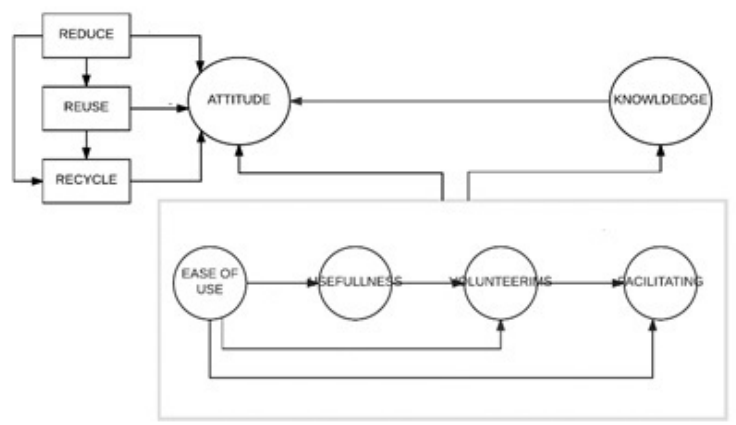

Fig. 1. Conceptual Framework on Attitude and Knowledge about Solid Waste Management

Other constructs that may influence attitude and knowledge are a) ease of use, b) usefulness, c) volunteerism, and d) facilitating conditions. Ease of Use is how the individual perceive the ease or difficulty in practicing SWM. This is similar to Azjen's Perceived Behavioral Control in his Theory 
of Planned Behavior. Usefulness describes the person's motivation based on his perceived importance of the behavior. Intrinsic motivation is defined in this study as volunteerism or the capacity to initiate or perform a behavior without social pressure. Facilitating conditions are factors which are necessary to execute the behavior. In this study, the context of facilitating conditions is operationalized by trash bins, waste collection, policies, among others.

\section{Methodology}

\section{A. Research Design}

A descriptive and correlational design was adopted in conducting the solid waste management survey for the food concessionaries of the university. The study involved all food concessionaries within the university compound. The survey was administered from June to July 2017 with sampling size of 37 represented by owners and employees of the food concessionaires. Subjects were informed about the purpose of the study through a seminarworkshop on waste management. Likewise, respondents of the study participated on a voluntary basis. Ethical considerations were taken in the data collection, privacy and confidentiality of information about subject and their responses.

\section{B. Research Instrument}

The study used a researcher-made questionnaire survey composed of four parts. The first part is the demographics, followed by attitudinal knowledge, ease of use, usefulness, volunteerism as second part. The third part is the facilitating condition items and the last is the list of problems. Items of the demographics made-up of 8 items. The second part of the survey proper is composed of 30 items. Using a five-point Likert Scale (not applicable, strongly disagree, agree, strongly agree). The items for Facilitating condition is made up of 8 items using Semantic Differential Scale (Never to All the Time). An open-ended question was included to list the problems encountered by the respondents. The listing of problems was answered in ordinal manner (the first item represents the worst problem, the second item is the lesser problem, and so on). Before the survey was conducted, it was pre-tested with the faculty/researchers of the college. Comments and suggestions were considered to improve the instrument. As to internal consistency, the instrument was tested using SPSS reliability tool (Cronbach Alpha). The Cronbach alpha for the instrument, composed of 30 items, is considered to be acceptable $(\alpha=0.755)$.

\section{Statistical Analysis}

First, a coding standard was designed for the different variables. The survey data were encoded using Excel ${ }^{\circledR}$ spreadsheet and based on the study's coding standards. IBM SPSS Statistics version 21.0 (B) was utilized to transform some variables, compute statistics, and generate charts and tables. SPSS functions such as compare means, correlate, linear regression, graphs were used produce the required statistics and for the analyses. Correlation coefficients were computed to examine the strength of association between variables, whereas ANOVA tested for significant difference in variability among the groups under study. The significance level was set at .05 . Table 1 is used to interpret the level of attitude, knowledge, ease of use, usefulness, and volunteerism of the subjects.

Table1. INTERPRETATION GUIDE FOR AgREEMENT/DisagreEMENT TO STATEMENTS

\begin{tabular}{|l|l|l|}
\hline From & To & Interpretation \\
\hline 0.00 & 0.44 & Not Applicable \\
\hline 0.45 & 1.44 & Strongly Disagree \\
\hline 1.45 & 2.44 & Disagree \\
\hline 2.45 & 3.44 & Agree \\
\hline 3.45 & 4.00 & Strongly Agree \\
\hline
\end{tabular}

Table 2 below is used to interpret the computed correlation coefficients in the study. Adjustments were made to accommodate rounding of the values in two decimal places.

Table 2. Interpretation Guide for Correlation CoEfFicient

\begin{tabular}{|l|l|l|}
\hline \multicolumn{2}{|l|}{$\begin{array}{l}\text { Correlation Coefficient } \\
r(+/-)\end{array}$} & \\
\cline { 1 - 2 } From & To & Interpretation \\
\hline 0.00 & 0.00 & No relationship \\
\hline 0.01 & 0.44 & Weak \\
\hline 0.45 & 0.64 & Moderate \\
\hline 0.65 & 0.94 & Strong \\
\hline 0.95 & 1.00 & Perfect \\
\hline
\end{tabular}

\section{RESULTS AND OBSERVATIONS}

The discussion on the results of the study is presented as follows : demographic profiles; attitude on reuse, recycle, reduce; significance in the relationship between knowledge and attitude on solid waste, and the associations of knowledge and attitude with mediating variables such as : ease of use, usefulness, volunteerism, and facilitating conditions, and summary of results. 


\section{A. Demographic Profiles}

The samples of the study were collected from the current food concessionaires $(\mathrm{N}=37)$ of the university. There are 70.3 percent female and 29.7 percent males in the study. Of these observations, almost 30 percent belongs to $46-55$ age group. The majority of respondents are employees of the food concessionaries $(70 \%)$ and they are mostly high school graduates $(43 \%)$ and college graduates $(40 \%)$ and the rest have finished or are taking post-graduate studies.

The food concessionaires are in the food business for an average of $8.9(\mathrm{SD}=4)$ years and are operating inside the university 5.3 $(\mathrm{SD}=4.34)$ years on the average. Majority of them (65\%) have attended seminars or trainings in solid waste management.

\section{B. Attitude on Reduce, Reuse, and Recycle}

The instrument of the study pertinent to attitude on solid waste is divided into three components : reduce, reuse, and recycle (also called 3Rs). The descriptive statistics per component and each statement under them is shown in the Table 3 . Overall, 12 out of 15 statements were agreed by the respondents except for the item numbers 6,8 , and 15 . The items or statements which were disagreed by respondents are (Item 6 is a negative stem question).

- Item 6 : I think that it more economical to reuse materials like plastic bags for our business.

- Item 8 : I don't want to reuse materials like bottles and plastic bags for our food business.

- Item 15 : It is easier to just dispose or sell my solid waste than doing the actual recycling.

The average of the items per component (3Rs) were calculated and Reduce registered the highest mean $(\mathrm{M}=3.016, \mathrm{SD}=.433)$ compared to Reuse, and Recycle. In summary, all the 3Rs were interpreted to "Agree" with the statements in the instrument (see Table 3).
Using One-Way Analysis of Variance (ANOVA) to compare the mean of Reduce, Reuse, and Recycle, the result suggested that there is a significant difference in the attitude among the 3Rs $[\mathrm{F}(2,108)=3.08, \mathrm{p}=.000]$. The boxplots in Fig. 2 show the dispersion of the $3 \mathrm{Rs}$ in terms of their quartiles, median, interquartile, and range.

Table 4. Analysis of Variance on Attitude REgARDING REDUCE, REUSE, AND RECYCLE

\begin{tabular}{lrrrrrr} 
ANOVA & \multicolumn{1}{c}{ Source of } & \multicolumn{1}{c}{ SS } & \multicolumn{1}{c}{ df } & \multicolumn{1}{c}{ F } & P-value & F crit \\
\hline Variation & 4.61121 & & 2.30560 & 8.60183 & 0.00034 & 3.08038 \\
\hline Between & 6 & 2 & 8 & 5 & 2 & 7 \\
Groups & 28.9479 & & 0.26803 & & & \\
Within Groups & 7 & 108 & 7 & & & \\
& & & & & & \\
& 33.5591 & & & & & \\
Total & 9 & 110 & & & & \\
\hline
\end{tabular}

Visual examination of the box-plot diagram revealed that Reduce have symmetrical quartile proportion and higher median to the Attitude variable. Reduce likewise shows a bigger dispersion compared to the other variables. Recycle has the least normality of distribution.

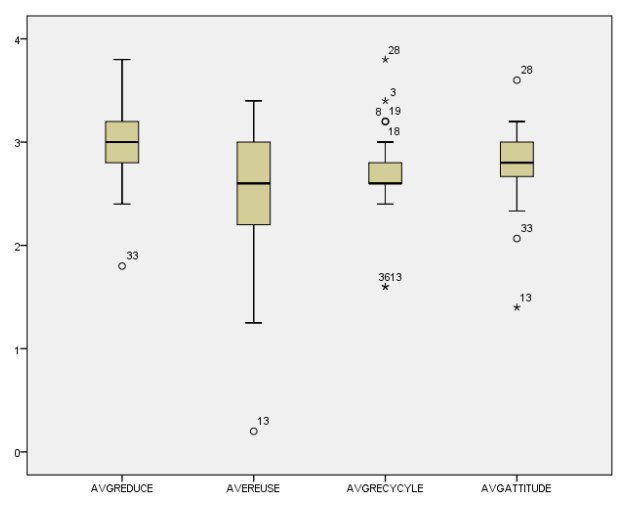

Fig. 2. Attitude Regarding Reduce, Reuse, and Recycle

Table 3. Descriptive Statistics for Per Group and Items

\begin{tabular}{|c|c|c|c|c|c|c|c|c|}
\hline \multicolumn{3}{|c|}{ REDUCE } & \multicolumn{3}{|c|}{ REUSE } & \multicolumn{3}{|c|}{ RECYCLE } \\
\hline ITEM & MEAN & STDEV & ITEM & MEAN & STDEV & ITEM & MEAN & STDEV \\
\hline Q1 & 2.89 & 0.94 & Q6 & 2.42 & 1.11 & Q11 & 2.78 & 0.79 \\
\hline Q2 & 2.81 & 0.74 & Q7 & 2.84 & 1.12 & Q12 & 2.63 & 1.06 \\
\hline Q3 & 3.27 & 0.84 & Q8 & 1.86 & 0.95 & Q13 & 3.22 & 0.63 \\
\hline Q4 & 3.08 & 0.80 & Q9 & 2.83 & 0.92 & Q14 & 2.70 & 1.05 \\
\hline Q5 & 3.03 & 0.60 & Q10 & 2.73 & 1.07 & Q15 & 2.17 & 0.94 \\
\hline MEAN & & & & & & & & \\
\hline & 3.02 & 0.43 & & 2.52 & 0.68 & & 2.70 & 0.39 \\
\hline
\end{tabular}




\section{Correlations and Significance of Reduce, Reuse, Recycle, and Attitude}

To establish the strength of relationship among the various factors i.e, reduce, reuse, recycle, and attitude, correlation coefficients were computed using Pearson's Product Moment Correlation (refer to Table 5). Reduce and Reuse have a positive moderate correlation with Attitude. Recycle and Attitude have significant correlation $(\mathrm{r}=0.382, \mathrm{p}<.05)$.

Table 5. Correlation of 3Rs And AtTitude

\begin{tabular}{|l|r|l|}
\hline \multicolumn{1}{|c|}{ Bivariate } & $\begin{array}{c}\text { Correlation } \\
\text { Coefficient }\end{array}$ & \multicolumn{1}{|c|}{ Interpretation } \\
\hline Reduce-Reuse & .040 & Weak \\
\hline Reduce- Recycle & .131 & Weak \\
\hline Reduce- Attitude & .488 & Moderate \\
\hline Reuse - Recycle & .112 & Weak \\
\hline Reuse- Attitude & .540 & Moderate \\
\hline Recycle - Attitude & $.382 *$ & Weak \\
\multicolumn{2}{|l}{ * Correlation significant at the .05 level (2-tailed) }
\end{tabular}

A multiple regression was calculated with reduce, reuse and recycle as independent variables and attitude as dependent variable. The linear regression model generated based on the 3 Rs as predictors of attitude is shown in the equation below:

\section{Predicted Attitude $=2.217+1.272 \times$ Reduce + $1.080 \times$ Reuse $+0.510 \times$ Recycle}

\section{Correlation of Knowledge and Attitude}

The items on the factor on Knowledge, comprising of 6 statements is described by the respondents at an average of $2.895(\mathrm{SD}=0.065)$ or interpreted as "Agree". The average of Attitude is $2.75(\mathrm{SD}=0.365)$ also classified under "Agree".

The variables knowledge and attitude were correlated and the correlation coefficient was found to be moderate positive relationship $(\mathrm{r}=0.418)$. The coefficient of determination $\left(\mathrm{r}^{2}\right)$ explains that knowledge accounts for the variance on attitude by 17 percent. The relationship of the two factors was found to be significant at .05 level $[\mathrm{F}(1,34)=7.182$, $\mathrm{p}$ $=.011]$. A visual inspection of the scatterplot suggests evidence of positive relationship between knowledge and attitude.

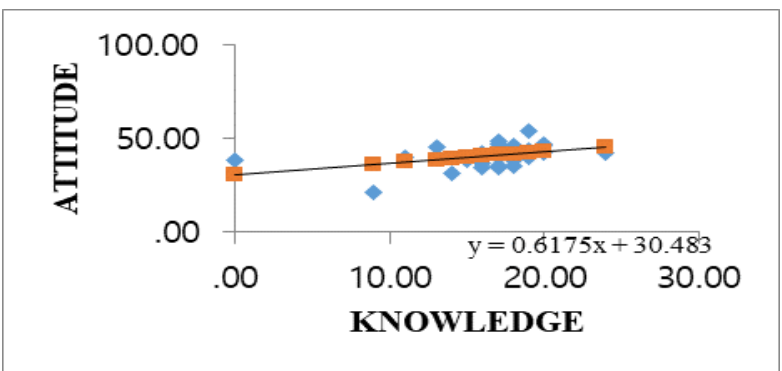

Fig. 3. Knowledge and Attitude Correlation and Linear Regression Model
The following formula is the linear regression model for knowledge as predictor for attitude on solid waste management. The derived linear model suggests that for every additional unit of knowledge, attitude increases by 0.617 unit. (unit of measure for the two variables are the same i.e., 0-4).

\section{Predicted Attitude $=\mathbf{3 0 . 4 8 3}+\mathbf{0 . 6 1 7} \times$ Knowledge}

\section{E. Correlation of Attitude with Mediating Factors}

Correlation was made to show the strength of the association between Attitude and the individual mediating factor. Based on the values of the correlation coefficient, the different mediating factors have weak and no significant relationship with the Attitude variable. The results suggest that the Ease of Use, Usefulness, Volunteerism, and Facilitating Condition factors have an almost independent relationship with Attitude factor (see Table 7).

Table 7. AtTitude And Mediating Factors CORRELATION

\begin{tabular}{|l|c|l|}
\hline \multicolumn{1}{|c|}{ MEDIATING } & $r$ & \multicolumn{1}{c|}{ INTERPRETATION } \\
\hline Ease of Use & 0.133 & Weak \\
\hline Usefulness & 0.160 & Weak \\
\hline Volunteerism & -0.069 & Weak (negative) \\
\hline $\begin{array}{l}\text { Facilitating } \\
\text { Conditions }\end{array}$ & -0.129 & Weak (negative) \\
\hline
\end{tabular}

\section{F. Correlation of Knowledge with Mediating Factors}

Knowledge was correlated with the mediating factors resulting to the coefficients listed in Table 8 . Almost all of the mediating variables are positively related with the dependent variable. The variables Ease of Use and Volunteerism have moderate correlations $(r=0.491, r=0.436$ respectively).

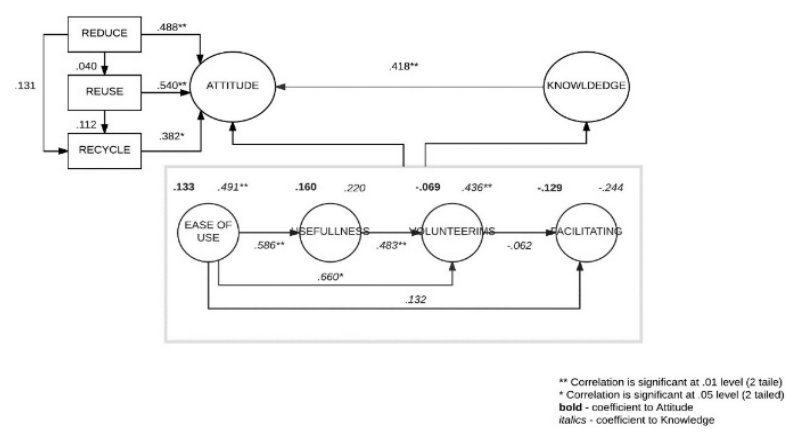

Fig. 4. Summary of Correlations of Variables and 
Usefulness and Facilitating conditions were found to have weak relationship with Knowledge. The results suggest that knowledge can be explained by factors mentioned specially by Ease of Use and Volunteerism. The inverse and weak relationship between Knowledge and Facilitating Conditions could probably mean that appreciation on garbage collections, policies, trash bin, etc. are not necessarily translated into adding value to knowledge.

Table 8. Correlations of Mediating Variables with KNOWLEDGE

\begin{tabular}{|l|c|l|}
\hline $\begin{array}{c}\text { MEDIATIN } \\
\text { G }\end{array}$ & $r$ & \multicolumn{1}{|c|}{ INTERPRETATION } \\
\hline Ease of Use & 0.491 & Moderate \\
\hline Usefulness & 0.220 & Weak \\
\hline Volunteerism & 0.436 & Moderate \\
\hline $\begin{array}{l}\text { Facilitating } \\
\text { Conditions }\end{array}$ & -0.244 & Weak (negative) \\
\hline
\end{tabular}

Overall, the mediating factors correlates more with Knowledge than Attitude. The degree of association is much prominent in Ease of Use and Volunteerism with Knowledge variable ( $\mathrm{r} .=.491, \mathrm{r}=.436)$. However, the Volunteerism and Attitude had the least correlation coefficient $(r=-.069)$.

\section{SUMMARY}

The summary of the correlations and their respective coefficients are illustrated in Fig. 4. The main finding is that the Attitude variable is positively correlated with Knowledge variable $(\mathrm{r}=.418, \mathrm{p}$ $<.05)$ and it also suggested that the relationship is significant similar to the population. Perceptions on the 3 Rs reduce, reuse, and recycle) positively correlates with Attitude and all three are found to be significantly correlated with Attitude. As to the mediating variables, i.e., Ease of Use, Usefulness, Volunteerism, and Facilitating Conditions, they are found to be explanatory with Knowledge rather than Attitude particularly with Ease of Use and Volunteerism. Other mediating factors seemed to show weak relationship with either Attitude or Knowledge.

\section{CONCLUSION}

The food concessionaries were found to possess a positive attitude on solid waste management on the 3Rs (reduce, reuse, and recycle). The perception of the respondents is consistent with the Hierarchy of Solid Waste Management particularly on the reduction process which is the most important stage in the processing of solid waste. The study confirms the findings of other researches on the subject of attitude and knowledge [6], [7], [8]. The high value of knowledge by respondents about solid waste contributes clearly to their positive attitude. Food concessionaires' knowledge is closely related to how they perceive the ease of use and voluntary participation to the university SWM program. The university, which is responsible in facilitating the conditions for compliance, have registered a high level of compliance to SWM. However, the food concessionaries level of knowledge has not established relationship with the variable of Facilitating Conditions. Attitude of the respondents on solid waste are not dependent on usefulness, ease of use, volunteerism, and facilitating conditions in contrast with Knowledge which correlates with factors such ease of use and volunteerism.

With the assumption that the calculated statistics is that of the population, the research found a probable basis for predicting the behavioral intent of the food concessionaires to practice solid waste management. Using the theory of Ajzen [10] and other studies, it can be deduced that there is a high likelihood that the food concessionaires will practice what they know and believe about the SWM program of the university given a consistent facilitating conditions and behavioral reinforcement.

\section{REFERENCES}

[1] PSA. (2016). Highlights of the Philippine Population 2015 Census of Population, 19 May 2016. [Online]. Available: https://www.psa.gov.ph/content/highlightsphilippine-population-2015-censuspopulation.

[2] NSWM. (2010). National Solid Waste Management Strategy 2012 - 2016, 2010. [Online]. Available: http://nswmc.emb.gov.ph/wpcontent/uploads/2016/07/NSWM-Strategy2012-2016.pdf.

[3] F. Omololu \& A. Lawal. Population Growth and Waste Management in Metropolitan Lagos," n.d.. [Online]. Available: http://www.academia.edu/11865312/Populati on_Growth_and_Waste_Management_in_M etropolitan_Lagos. 
[4] W. Bank. (2010). Waste Generation. [Online]. Available: http://siteresources.worldbank.org/INTURB ANDEVELOPMENT/Resources/3363871334852610766/Chap3.pdf.

[5] P. dela Cruz, E. Barloa \& L. Lapie. (2016). Knowledge, Attitudes, and Practices on Solid Waste Management in a Philippine State University. Journal of Environment and Earth Science, 146-153.

[6] J. Camba, M. Mondez \& A. Sampana. (2014). An Evaluation of Solid Waste Management System of the Bulacan State University, Bulacan State University, Malolos City.

[7] K. Pineda, R. Reyes \& R. Rosit. (2015). Assessment of Knowledge, Attitude, Practices and Willingness of the Stakeholders on the Solid Waste Management in Bulacan State University. Bulacan State University, Malolos City.

[8] K. Kolbe. (2015). Knowledge, Attitudes and Behavior regarding Waste Management in a Grammar and Comprehensive School in England. Journal of Teacher Education for Sustainability, 58-71.

[9] A. Desa. (2011). A Study on the Knowledge, Attitudes, Awareness Status and Behavior Concerning Solid Waste Management. Procedia Social and Behavioral Sciences, 643-648.

[10] I. Ajzen. (1991). The Theory of Planned Behavior. Organizational Behavior and Human Decision Processess, 179-211.

[11] MNSU. Theory of Planned Behavior. n.d.. [Online]. Available: http://www.mnsu.edu/its/academic/isalt_tpb. pdf. 